\title{
Metabolic profiling reveals altered sugar and secondary metabolism in response to UGPase overexpression in Populus
}

Raja S Payyavula ${ }^{1}$, Timothy J Tschaplinski ${ }^{1}$, Sara S Jawdy ${ }^{1}$, Robert W Sykes ${ }^{2}$, Gerald A Tuskan ${ }^{1}$ and Udaya C Kalluri ${ }^{1{ }^{*}}$

\begin{abstract}
Background: UDP-glucose pyrophosphorylase (UGPase) is a sugar-metabolizing enzyme (E.C. 2.7.7.9) that catalyzes a reversible reaction of UDP-glucose and pyrophosphate from glucose-1-phosphate and UTP. UDP-glucose is a key intermediate sugar that is channeled to multiple metabolic pathways. The functional role of UGPase in perennial woody plants is poorly understood.
\end{abstract}

Results: We characterized the functional role of a UGPase gene in Populus deltoides, PdUGPase2. Overexpression of the native gene resulted in increased leaf area and leaf-to-shoot biomass ratio but decreased shoot and root growth. Metabolomic analyses showed that manipulation of PdUGPase2 results in perturbations in primary, as well as secondary metabolism, resulting in reduced sugar and starch levels and increased phenolics, such as caffeoyl and feruloyl conjugates. While cellulose and lignin levels in the cell walls were not significantly altered, the syringyl-to-guaiacyl ratio was significantly reduced.

Conclusions: These results demonstrate that PdUGPase2 plays a key role in the tightly coupled primary and secondary metabolic pathways and perturbation in its function results in pronounced effects on growth and metabolism beyond cell wall biosynthesis of Populus.

Keywords: Metabolic profiling, Primary and secondary metabolism, Cell wall, UGPase, Populus

\section{Background}

Sucrose is the primary product of photosynthesis and the initial form of transported sugar in most plants. In higher plants, sucrose is hydrolyzed by either invertases to form glucose and fructose or sucrose synthases (SuSy) to form uridine diphosphate glucose (UDP-glucose) and fructose [1]. The carbon in glucose and fructose is further channeled into various primary or secondary metabolic pathways based on the spatiotemporal activity of metabolizing enzymes [2-4]. Sugar metabolizing enzymes have, therefore, been recognized as key gatekeepers of carbon allocation and partitioning pathways in plants [2,3]. The sugar, UDP-glucose, represents an important branch point in carbohydrate metabolism that can potentially be channeled directly for synthesis of starch, sucrose, cellulose

\footnotetext{
* Correspondence: kalluriudayc@ornl.gov

1 BioEnergy Science Center and Biosciences Division, Oak Ridge National Laboratory, Oak Ridge, TN 37831, USA

Full list of author information is available at the end of the article
}

or hemicellulose and pectin via synthesis of other nucleotide sugars such as UDP-glucuronic acid [2,3].

UDP-glucose pyrophopharylase (UGPase), also referred to as UGlcPP or uridine triphosphate glucose-1-P uridylyltransferase, is a sugar-metabolizing enzyme (E.C. 2.7.7.9) that catalyzes the reversible formation of UDPglucose and pyrophosphate from glucose-1-phosphate and uridine triphosphate (UTP). In photosynthetically active mature leaves, UGPase catalyzes the reaction in the direction of UDP-glucose and sucrose via coupled action of sucrose phosphate synthase (SPS) [reviewed in 5]. However, in sink organs, which depend on imported sucrose, UGPase is proposed to function in the conversion of UDP-glucose, which is produced via SuSy hydrolysis of sucrose, to glucose-1-phosphate [5].

Based on an analysis of the most recent version of the Populus trichocarpa genome and previous reports from hybrid aspen (Populus tremula $x$ tremuloides), rice (Oryza sativa) and Arabidopsis thaliana, UGPase genes appear to belong to small two-gene containing families [6-8]. 
UGPases have been purified from and expressed in several eukaryotic and prokaryotic organisms [9-11]. In vitro enzyme assays using AtUGPase1 and AtUGPase2 expressed in Escherichia coli suggested that both the isoforms have slight preference for the pyrophosphorylation direction of the reaction [12]. AtUGPase2 exhibited higher activity than that of AtUGPase1 in both directions, pyrophosphorolysis and synthesis [12]. The two isoforms showed no activity with other sugars such as ADP-glucose/ATP or galactose-1-P [12]. Antisense suppression of UGPase1 in Arabidopsis was reported to have no effect on plant growth, however, soluble carbohydrate and starch content was found to be reduced [13]. Tobacco (Nicotiana tabacum) plants overexpressing AxUGPase, a UGPase gene from Acetobacter xylinum, exhibited increased plant height in several lines, similar total dry weight relative to controls and no significant changes in sugars, starch or cellulose levels [14]. However, overexpression of the same bacterial UGPase in hybrid poplar (Populus alba x grandidentata) resulted in significantly reduced growth, increased levels of soluble sugars, starch and cellulose, and reduced lignin [15]. Three studies involving antisense downregulation of a native UGPase gene in potato (Solanum tuberosum) led to contrasting and inconclusive results. An early report suggested that a strong $95 \%$ reduction in UGPase transcripts and enzyme activity had no apparent effects on plant growth and sugar levels [16]. In two subsequent studies, however, antisense suppression of UGPase in potato resulted in significantly lower sucrose levels $[17,18]$. Based on microarray analysis of cell types representing the discrete stages of xylem development and wood formation in Populus, native UGPase expression was enhanced during late xylem cell expansion and secondary cell wall formation, suggesting a potential functional role for UGPase in UDP-glucose substrate provision during secondary cell wall formation [19]. In total, these results imply distinct host-specific-functional activities of UGPase in alternate plant species. A functional genomics investigation of native Populus UGPase gene has not been reported.

Given that plant metabolism is tightly regulated for coordinated plant response to various internal and external cues, and carbon flow links primary metabolism to secondary metabolism, it is surprising how little we know about the enzymes interconnecting the primary and secondary metabolic pathways. It is plausible that manipulation of sugar metabolizing enzymes, such as UGPase, can affect both primary sugar and secondary wall carbohydrate metabolism; however, it is unclear if and how such manipulations may quantitatively and qualitatively affect secondary metabolic pathways of shikimate, phenylpropanoid and lignin biosynthesis. Therefore, we have undertaken a detailed metabolic characterization of Populus deltoides plants overexpressing a native PdUGPase 2 gene. Transgenic plants had pronounced growth and metabolic changes relative to control plants. The changes in cell wall properties were, however, subtle with significantly reduced syringyl-to-guaiacyl ratios as one of the few alterations in transgenic cell walls. Overall, our results support a role for PdUGPase2 in carbohydrate metabolism, secondary metabolism and plant growth and development.

\section{Results and discussion}

\section{Phylogenetic analysis and expression of UGPase in} Populus

In several previous reports including Populus, the UGPase gene family has been reported to comprise of two genes [6-8]. A phylogenetic analysis was performed using two previously reported UGPase isoforms from Populus [8], orthologs from other plant species and AxUGPase as an outgroup. UGPase1 and UGPase2 cluster together closer than with any other UGPases (Figure 1). While PdUGPase1 and PdUGPase2, which appear to have arisen during the Salicoid duplication event [20], share more than $97 \%$ similarity ( $94 \%$ identity) with each other, they also share $92 \%$ similarity with AtUGPases vs. $90 \%$ with a gymnosperm UGPase (Additional file 1). There is a lower, $87 \%$, identity between the rice paralogs, OsUGPase1 and OsUGPase2, and a 93\% identity between the Arabidopsis paralogs, AtUGPase1 and AtUGPase2. The similarity of plant UGPases with the previously characterized AxUGPase averaged at 21\% (Additional file 1). The nucleotide binding loop (NB-loop) and insertion loop (I-loop), involved in dimer formation and stabilization [21,22], are conserved in AtUGPase and PdUGPase but absent in AxUGPase (Additional file 2), suggesting a potentially distinct enzymatic mechanism in plants involving dimer- or-oligomerization of proteins. In support of this hypothesis, it has been shown that the activity of barley UGPase is regulated by di- or oligomerization status of the protein, with monomer status representative of the active form of UGPase enzyme $[23,24]$.

Expression of the two PdUGPase genes was quantified in eight Populus tissue types including young leaf (leaf plastochron index 1, LPI 1), mature leaf (LPI-6), young stem (internodes 1 to 3), mature stem (internodes 6 to 8), petiole of a mature leaf, phloem (bark), xylem (stem scrapings) and root by quantitative reverse transcriptase PCR (qRT-PCR). Both isoforms were expressed in all tissues, with an overall higher expression level of UGPase1 relative to UGPase2 (Figure 2). Among all the tissues profiled, expression of PdUGPase1 was relatively higher in mature leaves and xylem, while expression of PdUGPase 2 was higher in young leaves and roots. Our results are consistent with previously published data involving alternate tissues and organs, which showed that UGPase1 


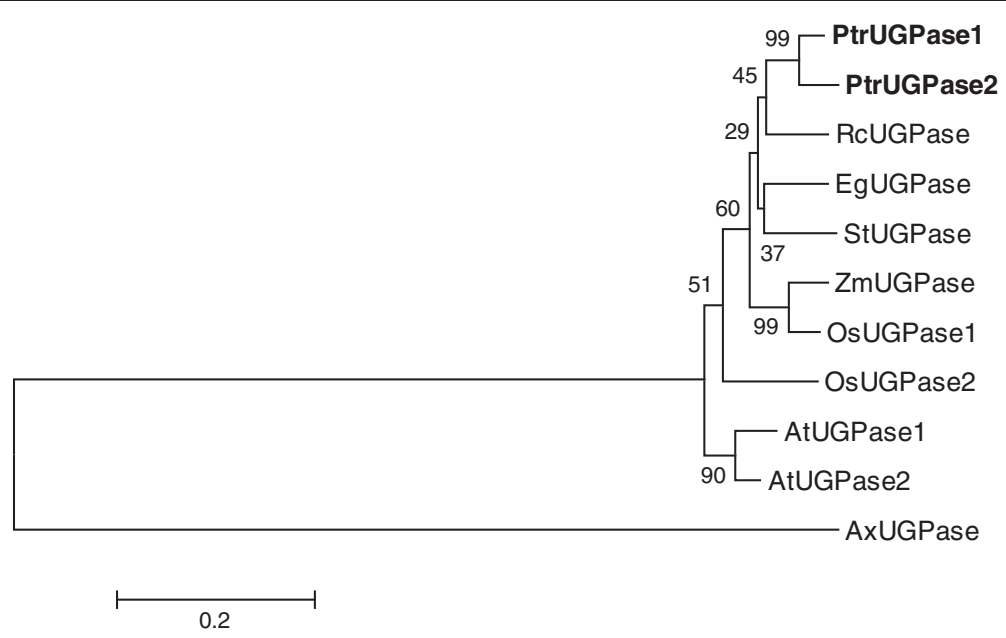

Figure 1 Phylogenetic analyses of UGPases from Populus and other species. Analysis was conducted in MEGA4 program using the Neighbor-Joining method. The percentage of replicate trees in which the associated taxa clustered together in the bootstrap test (500 replicates) are shown next to the branches. UGPases from this study are in bold. AtUGPase1 (Arabidopsis thaliana): AT3G03250; AtUGPase2: AT5G17310.2; AxUGPase (Acetobacter xylinum):AAA21888.1; EgUGPase (Eucalyptus grandis): ACF04278.1; OsUGPase1 (Oryza sativa): ABD57308; OsUGPase2: AF249880; PtrUGP1 (Populus trichocarpa): Potri.004G074400; PtrUGP2, Potri.017G144700; RcUGPase (Ricinus communis): XP_002526594.1; StUGPase (Solanum tuberosum): AAL99197.1; ZmUGPase (Zea mays): NP_001130742.1.

and UGPase 2 were abundant in flowers and young leaves [8]. In two additional studies, UGPase activity was also higher in xylem than in leaves $[14,15]$. In potato, where only one isoform has been reported, UGPase activity was abundant in sink tissues, such as stems and tubers [16]. In Arabidopsis, UGPase1 was reported to have enhanced expression in leaves and stems compared to flowers, whereas UGPase 2 had enhanced expression in flowers [25].

\section{Morphological characterization of PdUGPase2 overexpression plants}

Transgenic Populus deltoides plants overexpressing the PdUGPase2 gene (Potri.017G144700) under the control of a constitutive Polyubiquitin 3 (AtUBQ3, Accession
L05363) promoter were maintained and characterized under greenhouse conditions. In an initial transgenic phenotyping study, all PdUGPase 2 overexpression lines were found to be consistently shorter in height (20 to 50\%) with thinner stems (37 to 47\%) compared to control plants (Additional file 3). Assessment of an independently grown second set of transgenic plants confirmed that plant height and stem diameter were consistently smaller relative to controls (Figure 3A and B). Conversely, leaf area (35 to $55 \%$ ) and petiole length (45 to 55\%) were significantly greater in transgenics (Figure $3 \mathrm{C}$ and D), though total leaf dry weight was reduced as a result of fewer leaves (Figure 4A). Additionally, reduced plant height and stem diameter resulted in a significant reduction in stem dry

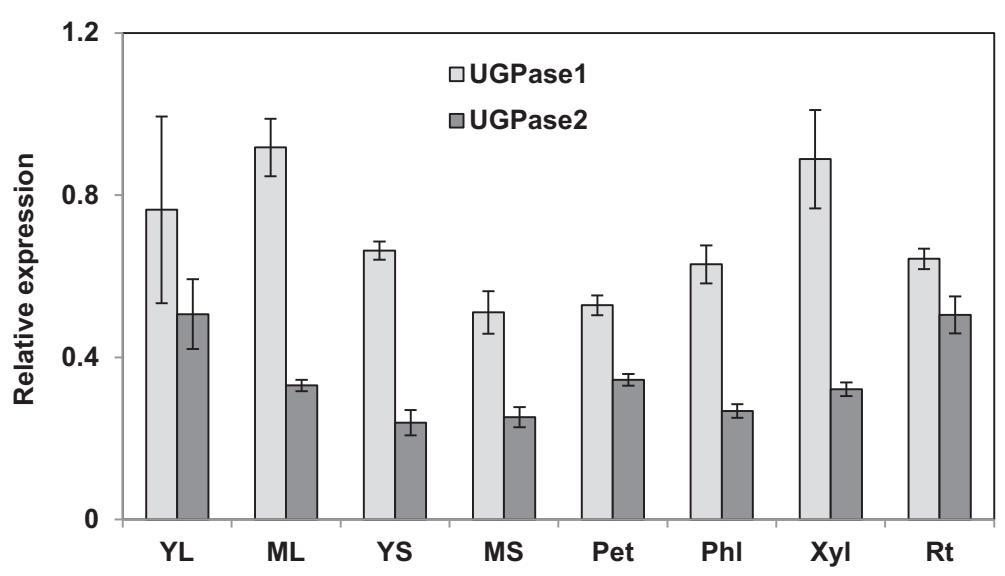

Figure 2 Relative expression of UGPase isoforms in different tissues. Expression of UGPasel and UGPase2 in $Y L$, young leaf, ML, mature leaf, YS, young stem, MS, mature stem, Pet, petiole, Phl, phloem, Xyl, xylem and Rt, root. Data represent means \pm SE $(n=3)$. Relative expression was calculated based on the expression of reference genes Ubiquitin-conjugating enzyme E2 (Potri.006G205700) and 18S ribosomal RNA (AF206999). 

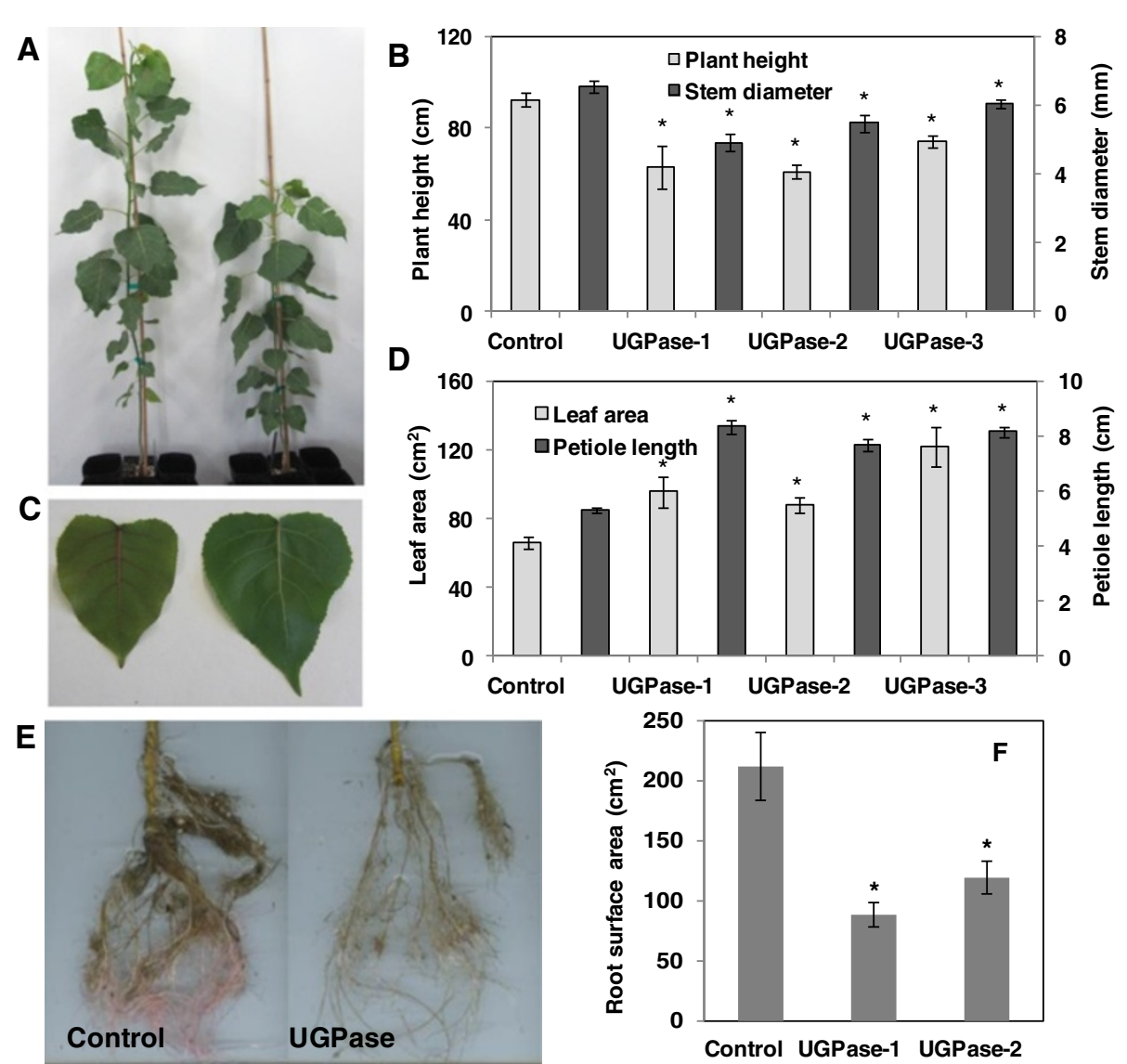

Figure 3 Phenotypic characterization of UGPase2 overexpression lines. Differences in plant height (A and B) and stem diameter (B), leaf area $(\mathbf{C}$ and $\mathbf{D})$ petiole length $(\mathbf{D})$ root system $(\mathbf{E})$ and root surface area $(\mathbf{F})$ among control and UGPase2 transgenic plants. Data represent means \pm SE $(n \geq 3) .{ }^{*}$ indicates statistically significant, $p \leq 0.05$ based on Student's $t$-tests.

weight (Figure 4B). When compared to controls, leafto-stem biomass ratio doubled (Figure 4C), whereas root weight and root surface area were reduced (50\%) in transgenic plants (Figures 3E, F and 4D). We quantified UGPase 2 transcript levels in mature leaf petioles of three selected lines and found that PdUGPase2 expression increased 2-fold (Additional file 4). Our results suggest that modest changes in native UGPase2 levels can have pronounced morphological effects on plant phenotype in woody perennials such as Populus.

Previous studies of suppression or overexpression of UGPase in other plant species have reported phenotypes ranging from no relative change to severely reduced plant height. In potato, for example, despite a strong $96 \%$ reduction in UGPase enzyme activity as a result of antisense suppression, plant growth or tuber development was found to be unaffected [16]. In Arabidopsis, the T-DNA mutants of UGPase 1, UGPase 2 and double knockouts had no effect on growth rate, biomass production and flowering in mature plants, however, it was noted that young plantlets in agar had reduced hypocotyl and root length [25]. A small increase in plant height without apparent effect on dry weight was reported for tobacco plants overexpressing the Acetobacter UGPase under control of a constitutively expressed $35 \mathrm{~S}$ promoter from cauliflower mosaic virus or a vascular-specific parsley 4-coumarate: CoA ligase (4CL) promoter [14]. In Populus plants overexpressing the same bacterial UGPase under the control of a constitutively expressed 35S promoter, however, was reported to display significant reduction in plant height, stem diameter, leaf area and internode length [15]. Contrastingly, we have observed that the leaf area is dramatically greater in PdUGPase 2 plants relative to control. The distinct aspect of the present work relative to the previous transgenic Populus UGPase study [15] is the use of a native gene from Populus deltoides here. Given the fact that PdUGPase2 has only a $20 \%$ amino acid similarity with that of Acetobacter UGPase (Additional file 1), a difference between phenotypic responses of plants overexpressing the two genes is not unexpected. 

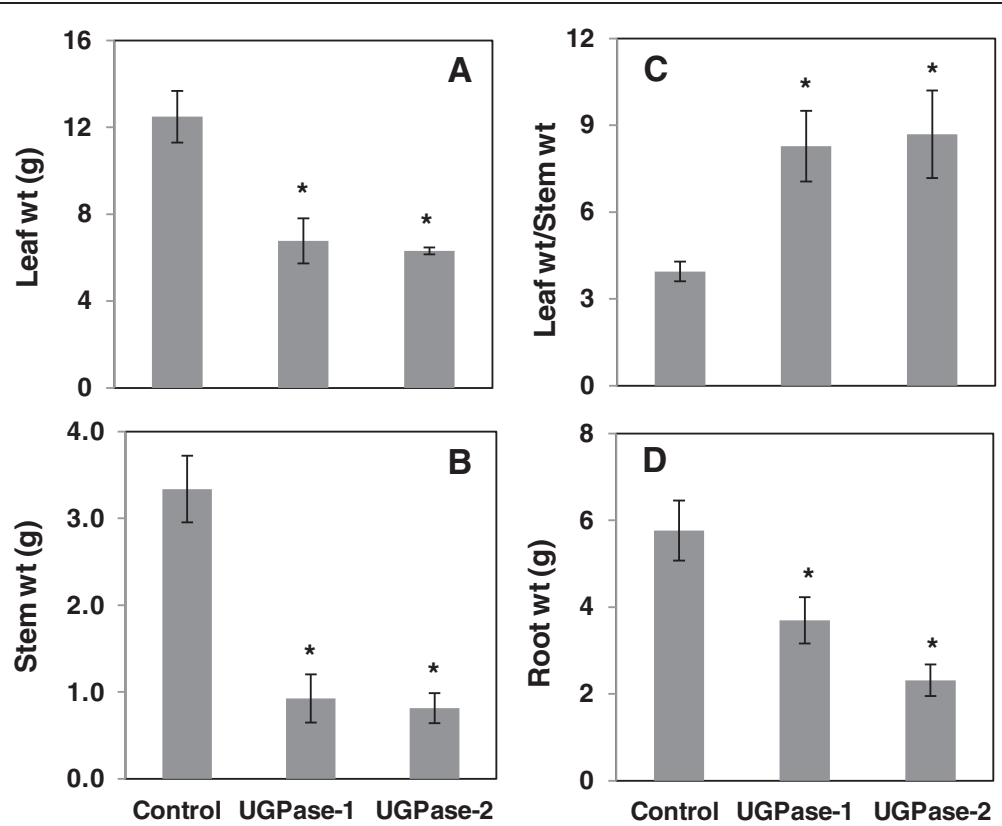

Figure 4 Dry weight of different plant parts in control and two UGPase2 transgenic lines. Dry weights corresponding to leaf (A), stem (B), and root $(\mathbf{D})$ and the ratio of leaf to stem dry weight $(\mathbf{C})$ are presented. Data represent means \pm SE $(n=3)$. *indicates statistically significant, $p \leq 0.05$ based on Student's t-tests.

\section{Cell wall composition of PdUGPase2 overexpressing Populus}

HPLC analysis of stem cell wall sugar composition showed that glucose and xylose were the most abundant sugars in all samples as expected (Table 1). Among glucose, xylose, galactose, arabinose and mannose, significant changes were observed only in mannose levels, with lower mannose levels in transgenic samples. While cellulose and lignin content appeared unaffected; the syringyl-to-guaiacyl $(\mathrm{S} / \mathrm{G})$ ratio of lignin was significantly reduced in transgenic lines (Figure 5A - C). In order to explore whether overexpression of UGPase 2 has any effect on the transcription of carbohydrate metabolism or/and cellulose pathway, a subset of sugar metabolism and cellulose synthesis-related genes were studied (Figure 6). The panel of genes that we studied included, sucrose transporters, SUT3, linked previously to enhanced cellulose production [26], and SUT4, linked to carbon partitioning [27]; genes that encode sucrose hydrolyzing enzymes [1], vacuolar invertases, VIN2 and VIN3; neutral invertase, NIN8 [27]. Additionally, the secondary cell wall associated cellulose synthase (Ces $A$ ) genes, CesA7B and CesA8B, and KORRIGAN (KOR) genes, $K O R 1$ and $K O R 2$, were included based on previously reports of proposed roles in cellulose biosynthesis [28-30]. SuSy1 and Susy2 transcripts and corresponding proteins have been shown to be elevated in tissue contexts with enhanced cellulose biosynthesis such as secondary xylem development and tension stress response [31,32]. Furthermore, a functional role for SuSy in supplying sugars for cellulose synthesis has been proposed [33]. The expression of most sugar metabolism genes was not significantly altered except SUT3 which was significantly higher in all the three transgenic lines (Figure 6A). Whether SUT3 has a direct role in sucrose transport and carbon partitioning in Populus is as yet unanswered. Of the surveyed cellulose pathway genes, CesA and SuSy isoforms were not significantly altered, but KOR1 and KOR2 were significantly increased in young leaves of transgenic lines (Figure 6B). These results suggest that overexpression of PdUGPase 2 may be associated with modest changes in transcript levels of

Table 1 Structural carbohydrate content $\left(\mathrm{mg} \mathrm{g}^{-1}\right)$ in stems of control and three UGPase2 transgenic lines

\begin{tabular}{lllllll}
\hline & Cellobiose & Glucose & Xylose & Galactose & Arabinose & Mannose \\
\hline Control & $3.54 \pm 0.06$ & $35.1 \pm 0.62$ & $15.6 \pm 0.17$ & $1.69 \pm 0.04$ & $0.92 \pm 0.02$ & $1.93 \pm 0.05$ \\
UGPase-1 & $3.44 \pm 0.17$ & $34.1 \pm 0.85$ & $15.6 \pm 0.18$ & $1.62 \pm 0.08$ & $0.95 \pm 0.05$ & $1.36^{*} \pm 0.06$ \\
UGPase-2 & $3.67 \pm 0.14$ & $34.1 \pm 0.60$ & $16.1 \pm 0.23$ & $1.28 \pm 0.30$ & $0.99 \pm 0.03$ & $1.59^{*} \pm 0.07$ \\
UGPase-3 & $3.44 \pm 0.12$ & $33.3 \pm 0.82$ & $15.8 \pm 0.24$ & $1.75 \pm 0.10$ & $0.97 \pm 0.05$ & $1.49^{*} \pm 0.06$ \\
\hline
\end{tabular}



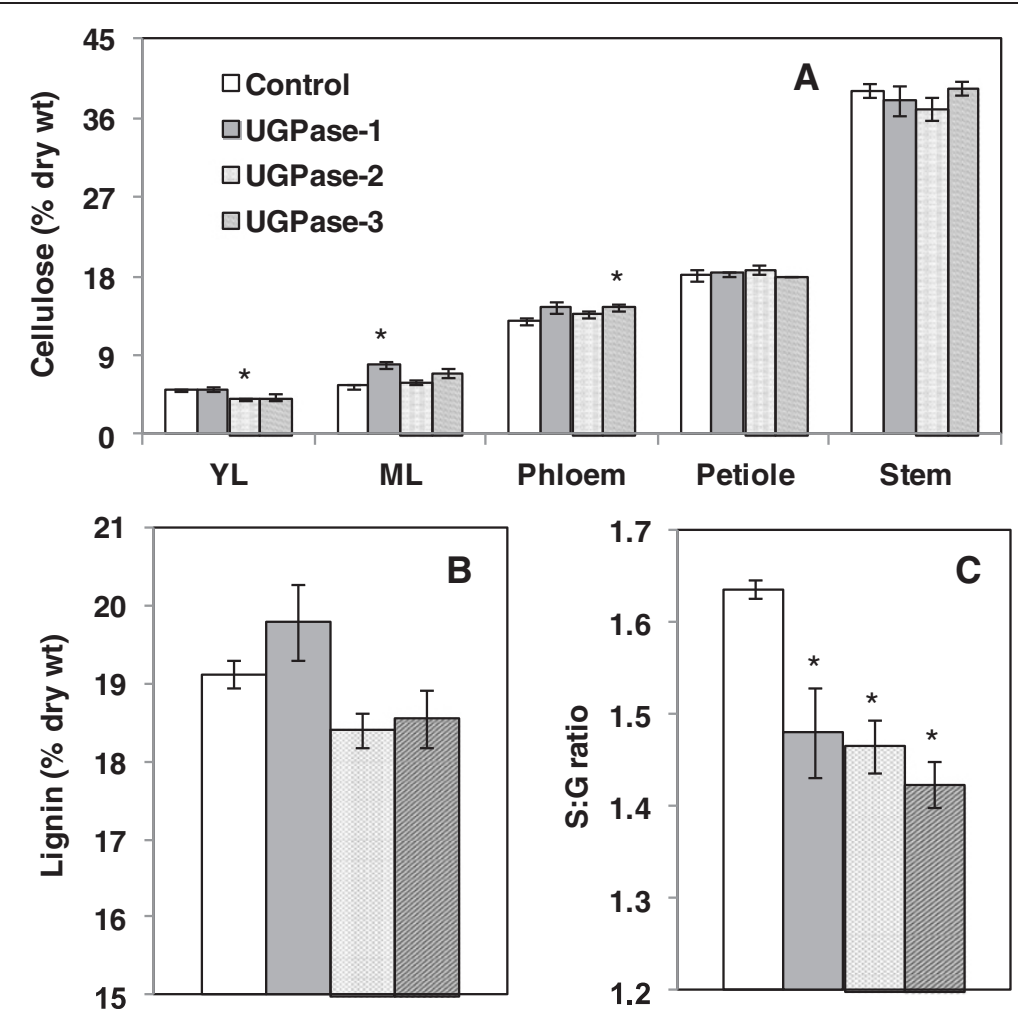

Figure 5 Cell wall composition analysis in control and three UGPase2 overexpression lines. A. Cellulose levels in different tissues, B. Lignin and $\mathbf{C}$. syringyl $(S)$ to guaiacyl $(G)$ ratio in stems of control and transgenic lines. $Y L$ and $M L$ represent young and mature leaf, respectively. Data represent means $\pm S E(n \geq 3)$. *indicates statistically significant, $p \leq 0.05$ based on Student's $t$-tests.

cellulose pathway-associated genes but that does not translate into changes in cellulose levels (Figure 5A). The unchanged cellulose levels in overexpression lines of PdUGPase 2 contradicts with previous reports where cellulose levels were increased in AxUGPase overexpression lines [15]. While the implication of low sequence identity between the bacterial and Populus UGPase isoforms on enzyme activity is yet to be clarified, the functional activity of AxUGPase has shown to complement cellulose negative mutant phenotype by channeling sugar substrate for cellulose synthesis [34].

\section{Metabolic profiles of xylem, phloem and leaves of PdGPase2 overexpressing Populus}

Secondary metabolites such as phenolics and tannins are derived from the carbon in glucose channeled via the shikimate and phenylpropanoid pathway [4]. In order to characterize the broader changes in secondary metabolism, we undertook a detailed metabolomics study. As expected, the xylem tissue sample, which contain dead xylem cells, had the fewest statistically significant metabolite differences $(\mathrm{p} \leq 0.05)$ between PdUGPase 2 overexpression lines and control plants (Additional file 5). Still, among the significant differences, shikimic acid and maleic acid were reduced to $55 \%$ and $26 \%$ of controls, respectively. Several amino acids [i.e., asparagine, glutamine, aspartic acid, $\gamma$-amino-butyric acid and 5-oxo-proline] and phenolic glycosides [i.e., including salicylic acid and its glucoside, salicylic acid-2-O-glucoside, 2, 5-dihydroxybkbenzoic acid-5-O-glucoside, 2-methoxyhydroquinone-1-Oglucoside, 2-methoxyhydroquinone-4-O-glucoside, salicin, a partially identified gallic acid ester of a dihydroxybenzoic acid glycoside at retention time (RT) $15.83 \mathrm{~min}$, and an un-

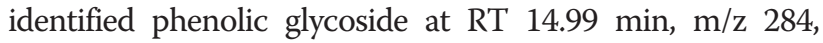
$269]$ were increased $1.4 x-3.0 x$ in the transgenics. Additionally, glycerol-1/3-phosphate and $\alpha$-monopalmitin, two fatty acid-related metabolites, were moderately elevated 1.2-1.3x.

We have observed a significant increase $(68 \%)$ in total phenolic levels in transgenic samples relative to control (Additional file 5). The increase in phenolics may be correlated with the decreased plant height and altered lignin composition. Down-regulation of Cinnamoyl-CoA reductase $(C C R)$, a gene in monolignol pathway in Populus was reported to affect plant height, lignin content, S/G ratio, and reduction in several sugars including mannose, however, the levels of phenolics were found to be elevated [35]. Antisense down-regulation of $4 C L$ gene in Populus has been reported to result in reduced lignin content and plant height but increased levels of phenolics [36]. In the PdUGPase plants studies here, we 

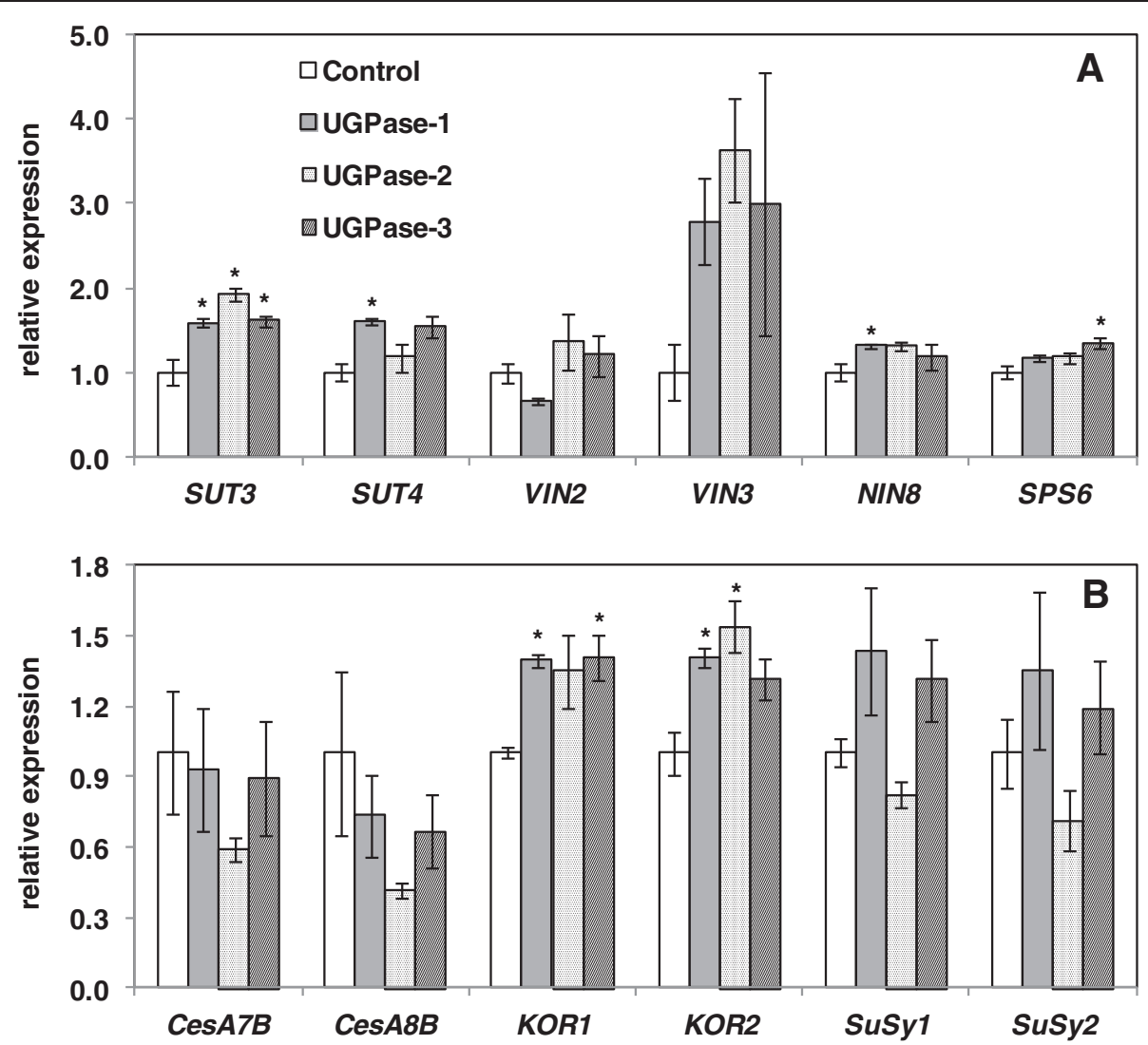

Figure 6 Expression of selected sugar metabolism (A) and cellulose pathway genes (B) in young leaves of control and UGPase2 overexpression lines. Relative expression was calculated based on the expression of reference genes Ubiquitin-conjugating enzyme E2 and $18 \mathrm{~S}$ ribosomal RNA. SUT, Sucrose transporter; VIN, Vacuolar invertase; NIN, Neutral invertase; SPS, Sucrose phosphate synthase; CesA, Cellulose synthase; SuSy, Sucrose synthase; KOR, KORRIGAN. Accessions: SUT3, Potri.019G085800; SUT4, Potri.002G106900; VIN2, Potri.003G112600; VIN3, Potri.015G127100; NIN8, Potri.019G082000; SPS6, Potri.018G124700; CesA7b, Potri.018G103900; CesA8b, Potri.004G059600; KOR1, Poptri.003G151700; KOR2, Poptri.001G078900; SuSy1, Potri.018G063500; SuSy2, Potri.006G136700;18S, AF206999; UBCc, Potri.006G205700. Data represent means \pm SE $(n=3)$. *indicates statistically significant, $p \leq 0.05$ based on Student's t-tests.

observe a significant reduction in plant height and S/G ratio, and an increase in phenolics.

Many more metabolites were affected in the phloem of UGPase 2 transgenic lines relative to control plants (Additional file 6). Similar responses included the reduction of shikimic acid and increases in 2, 5-dihydroxybenzoic acid-5-O-glucoside, salicylic acid-2-O-glucoside and salicin. An example of a contrasting response included the decline in the phenolic acid glycoside (RT 14.58, m/z 284, 269) that was elevated in the xylem of UGPase 2 plants. Additionally, there were declines in soluble sugars in the phloem of UGPase 2 lines, including decreases in fructose, galactose, glucose and raffinose ranging from 40-68\%, compared to that of controls. Many aromatic metabolites were reduced, including catechin, catechol, salicyl alcohol, salicylic acid and higher-order salicylates, including salicortin and $\alpha$-salicyloylsalicin and five caffeoylconjugates, two of which (eluting at RT 20.69 and $20.77 \mathrm{~min}$ ) were not detected in plants overexpressing UGPase2 (Additional file 7). These latter declines were coupled with a decline in sinapyl alcohol and its glucoside, syringin, but not coniferyl alcohol nor its glucoside, coniferin. These observations sit in contrast with the large number of increases in caffeic acid and other caffeoyl-conjugates and feruloyl-conjugates in the phloem of UGPase 2 transgenic lines. Overall, both the total phenolic metabolites and soluble sugars were reduced in the phloem of UGPase 2 lines relative to the levels measured in xylem.

UDP-glucose acts as a substrate for glycosylation of small secondary metabolites [37,38]. The effect of UGPase 2 overexpression on the ratio of aglycones to glycosides of phenolics was measured in phloem samples of control and transgenic plants (Additional file 8). We found that as compared to controls, UGPase 2 transgenic plants have a greater glycoside to aglycone ratio for the salicylates and a few other aromatic acids, but not for the monolignol glycosides. The most prominent change was a 5-fold increase in salicin, a possible precursor of higher-order phenolic glycosides. 
In general, metabolomic responses in leaves of PdUGPase 2 overexpression lines were similar to those in the phloem (Additional files 9, 10). In contrast with stem phloem responses, caffeoylpopuloside and a caffeoylconjugate at RT 19.57 declined. Additionally, cis- and trans-3-O-caffeoylquinic acids were enhanced in leaves, as were three other caffeoyl-conjugates (RT 19.14, 19.89 18.14). Two caffeoyl-glycoside conjugates at RT 19.14 and 19.31 were not detectable in leaves of control plants (Additional file 10). Other benzoic acid-related and salicylic acid-related metabolites in the transgenics, including 2,3-dihydroxybenzoic acid-3-O-glucoside, a partially identified dihydroxybenzoic acid-gallic acid glycoside (RT 15.83), salicyl alcohol, catechol, and salicyloylsalicortin, were higher. Reductions were observed in fatty acid-related metabolites, including glyceric acid and, mono- and di-galactosylglycerol. Neither salicylic acid nor its glucoside were significantly different between in leaves of transgenic and control plants. Furthermore, calorimetric assays showed that phenolic content was higher, and tannin, starch, sucrose, and glucose levels were lower in transgenic leaves relative to control (Figure 7, Table 2).

\section{Similar metabolite phenotypes of Populus plants misexpressing two distinct candidate cell wall biosynthesis genes}

It is interesting to note that many of the metabolic responses reported here were similarly observed in a recent study of $P$. deltoides KOR-like RNAi knockdown mutants (Payyavula et al. in review). That is, with both overexpression of PdUGPase 2 in the present study and knockdown of KOR-like genes, there was an accumulation of caffeoyl-conjugates, including caffeoylpopuloside. Both types of transgenics also had declines in the same types of caffeoyl-conjugates.

The close parallel in the metabolic phenotypes between these different transgenics was also evident in the leaves, where both exhibited declines in syringin and caffeoyl conjugates at RT 20.69 and $20.31 \mathrm{~min}$ and increases in cis- and trans-3-O-caffeoylquinic acid and caffeoyl-conjugates at RT 19.14, 19.31, 18.14, 21.52, $20.92,19.89,19.53,18.24 \mathrm{~min}$. Given that these two groups of genes have been proposed to play a role in cell wall biosynthesis and remodeling pathways [29,39,40], the premise of observed similarities in metabolite levels in response to perturbations of cell wall formation is interesting.

With S-lignin deposition affected more than G-lignin, there may be a reduced flux of carbon to lignin precursors at the terminus of the lignin pathway. This hypothesis is supported by accumulation of phenolic acid (caffeoyl and feruloyl) conjugates upstream of monolignol synthesis with shikimic acid and other unidentified moieties (Additional files 5, 6 and 7). In CCR down-regulated Populus, the decrease in lignin and $\mathrm{S} / \mathrm{G}$ ratio was accompanied by an increase in feruloyl conjugates [35]. A thorough characterization of accumulating caffeoyl-conjugates is merited, likely revealing the nature of lignin or cell wall storage components that have not previously been documented. The greater number and nature of metabolite responses in phloem versus xylem suggests that metabolite trafficking between these organs plays a major role in shuttling, modifying and storing precursors that are directly not incorporated into the cell wall. Therefore, metabolite trafficking mechanisms in cell wall assembly also merit more attention. Additional detailed study of alterations in cell wallrelated properties such as cellulose crystallinity, lignincarbohydrate cross-linkages and structural features revealed by electron microscopy, as well as stem strength properties are needed to support a possible explanation of the observed similarity in metabolite profiles as a potential consequence of the aberrant cell wall formation in PdUGPase overexpression and PdKOR knockdown transgenic plants.

\section{Overexpression of a bacterial or Populus UGPase result in contrasting phenotypes}

In tobacco, overexpression of AxUGPase under the control of a cauliflower mosaic virus $35 S$ promoter or a vascular-specific parsley $4 \mathrm{CL}$ promoter resulted in a slight increase in plant height via increased internode length [14]. However, total plant dry weight was unaltered. Although overexpression of the AxUGPase was evident at the transcript level, in both leaves and xylem, UGPase enzyme activity was not significantly altered. In contrast, overexpression of the same AxUGPase under the control of a $35 S$ promoter in hybrid poplar resulted in significant reduction in plant height, stem diameter, leaf area and internode length [15]. While sucrose and glucose levels were greater in hybrid poplar overexpressing AxUGPase [15], their levels were lower in Populus overexpressing the native UGPase2 under the control of a Ubiquitin promoter. Moreover, leaf area of transgenic hybrid poplar plants overexpressing AxUGPase were nearly $75 \%$ smaller relative to control, while Populus plants overexpressing native UGPase2 resulted in increased leaf area by a factor of two (Figure 3D). One plausible explanation is that the differential conserved domain composition of AxUGPase and PdUGPase 2 enzymes (Additional file 1) contributes to differential utilization of sugars synthesized in transgenic leaves towards either leaf growth or storage purposes.

At the metabolic level, our results also contrast with those reported for hybrid poplar overexpressing a bacterial UGPase, such that there was a $233 \mathrm{x}$ increase in salicylic acid-2-O-glucoside in developing xylem, 

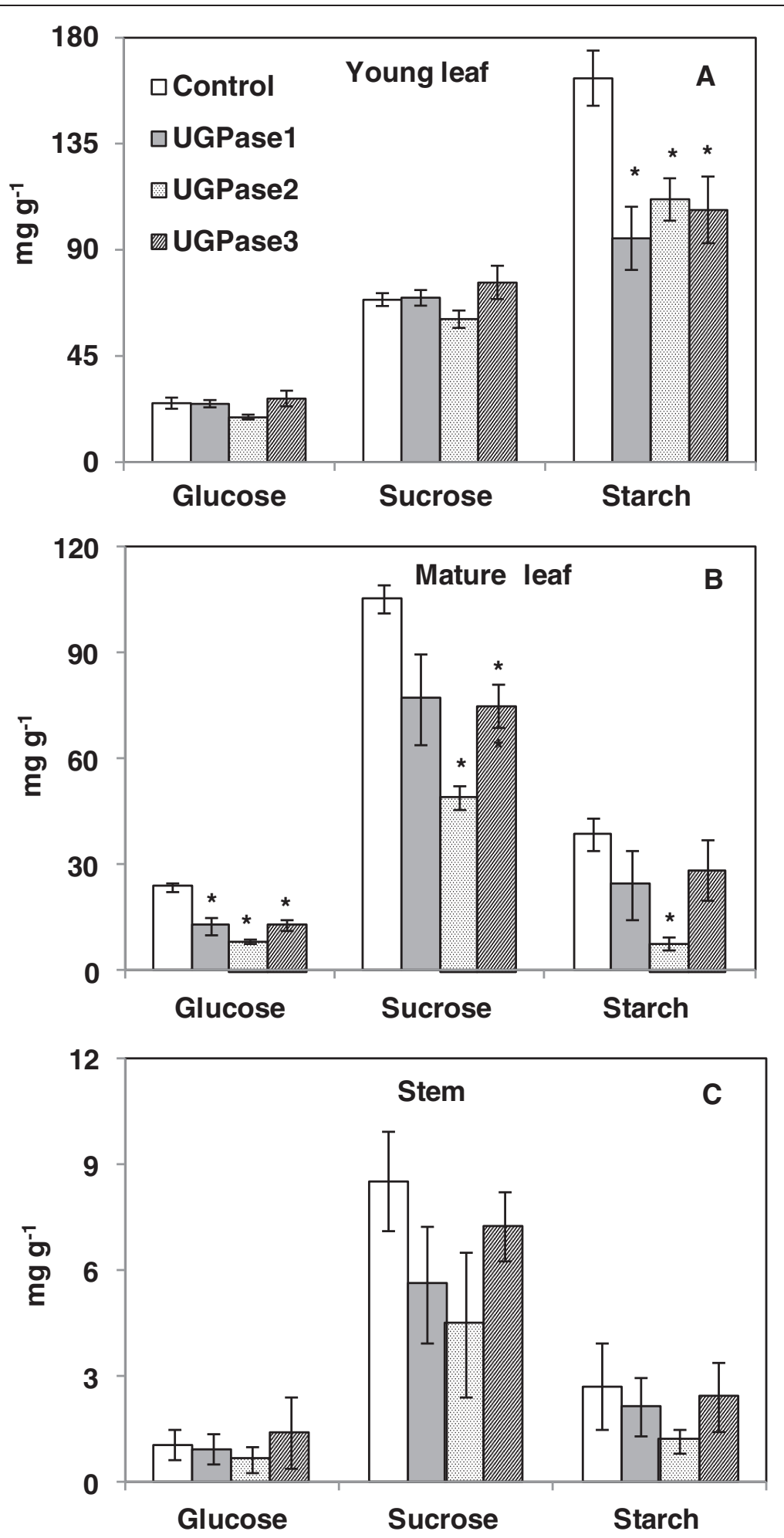

Figure 7 Estimation of non-structural carbohydrates in control and UGPase2 transgenic lines. Levels of glucose, sucrose and starch in young leaves (A), mature leaves (B) and stems (C) are presented. Data represent means \pm SE $(n \geq 3) .{ }^{*}$ indicates statistically significant, $p \leq 0.05$ based on Student's t-tests. 
Table 2 Levels of phenolics and tannins from mature leaves and petiole of control and three UGPase2 overexpression lines

\begin{tabular}{|c|c|c|c|c|}
\hline & \multicolumn{2}{|l|}{ Leaf } & \multicolumn{2}{|l|}{ Petiole } \\
\hline & $\begin{array}{l}\text { Phenolics } \\
\mathrm{mg} \mathrm{g}^{-1}\end{array}$ & $\begin{array}{l}\text { Tannins } \\
\mathrm{OD} \mathrm{g}^{-1}\end{array}$ & $\begin{array}{l}\text { Phenolics } \\
\mathrm{mg} \mathrm{g}^{-1}\end{array}$ & $\begin{array}{l}\text { Tannins } \\
\mathrm{OD} \mathrm{g}^{-1}\end{array}$ \\
\hline Control & $130.0 \pm 5.0$ & $30.5 \pm 3.1$ & $114.5 \pm 4.2$ & $73.2 \pm 4.7$ \\
\hline UGPase-1 & $141.2 \pm 6.7$ & $22.4 \pm 2.8$ & $65.3^{*} \pm 6.0$ & $20.5^{*} \pm 5.7$ \\
\hline UGPase-2 & $156.1^{*} \pm 7.7$ & $21.3 \pm 6.3$ & $73.0^{*} \pm 3.6$ & $16.6^{*} \pm 3.5$ \\
\hline UGPase-3 & $150.3 \pm 13.0$ & $17.1^{*} \pm 1.3$ & $72.6^{*} \pm 5.9$ & $20.9^{*} \pm 2.2$ \\
\hline
\end{tabular}

Data represent means $\pm S E(n \geq 3)$. *indicates statistically significant, $p \leq 0.05$ based on Student's $t$-tests.

relatively no change in other phenolic glycosides and elevated soluble sugars using the AxUGPase construct [15]. In our study, salicylic acid-2-O-glucoside was only modestly elevated (2.70x) in xylem, along with a number of other phenolic glycosides with a similar magnitude of response of 1.39-2.65x. The greatest number and magnitude of metabolite responses were observed in phloem tissue of the stem, where both soluble sugars and total phenolic metabolites declined (Additional file 6). A decline in higher-order salicylates was offset by large accumulations of conjugates of caffeic acid and ferulic acid. In contrast to the study undertaken by Coleman et al. [15], where lignin content was reported to be reduced and the S/G ratio increased, transgenic stem lignin content in the present study was unchanged while S/G ratio decreased. This change in lignin composition (decrease in $\mathrm{S}$ units of lignin) co-occurred with an increase in the concentrations of monolignols and their glucosides in the phloem of stems. While coniferyl alcohol and its glucoside, coniferin were unaltered in phloem of UGPase 2 plants, sinapyl alcohol and its glucoside, syringin, were both greatly reduced.

\section{Conclusion}

The present report addresses a gap in our understanding of the functional role of UGPase 2 in woody perennials such as Populus. We have presented metabolomicsbased evidence in support of a functional role for a plant UGPase 2 in the tightly coupled primary and secondary metabolic pathways. Our results are in contrast with previously reported results based on overexpression of a low-identity bacterial UGPase in hybrid poplar. The observed lack of impact on cellulose levels and contrasting plant morphology of Populus UGPase 2 overexpression lines lead to the hypothesis that plant UGPases may have evolved to play a functional role divergent from that reported for bacterial UGPase. Future research aimed at clarifying the precise enzymatic roles and pathway contexts of UGPase 2 would provide mechanistic insights into the pronounced phenotypic effects resulting from overexpression of a native UGPase 2 in Populus.

\section{Methods}

\section{Sequence and phylogenetic analyses}

Protein sequence information for Populus was collected from Phytozome v9.1 [http://www.phytozome.net/cgibin/gbrowse/Populus/]: Populus trichocarpa v3.0 [20,41]. Other sequence information (e.g. nucleotide sequence of genes) was obtained from NCBI database. The amino acid sequences were aligned using ClustalW program and phylogenetic tree was developed using MEGA (Molecular Evolutionary Genetics Analysis) software with neighbor joining method using 500 independent bootstrap runs [42]. Protein sequence similarity percentage was calculated with GeneDoc program [43].

\section{Plant materials}

An overexpression construct was developed by cloning the full-length coding sequence of PdUGPase2 (Potri.017G144700, also referred to in the present work as PtrUGPase 2 or UGPase2) from Populus deltoides under the control of Ubiquitin 3 promoter (Accession L05363) in the pAGW560 binary vector. Agrobacterium-based transformation was performed at ArborGen LLC, Ridgeville, SC. Transgenics, along with empty vector control plants (also referred to in this report as control or as control plants or lines), were propagated at $25^{\circ} \mathrm{C}$ and $16 \mathrm{~h}$ day light in greenhouses at Oak Ridge National Laboratory, Oak Ridge, TN. Plant propagation was performed using greenwood stem cuttings. Initially, stem cuttings were propagated in small leach tubes and grown to a plant height of approximately $50 \mathrm{~cm}$, following which, the plants were moved to larger pots and grown under automated drip irrigation and fertilization systems. In our preliminary studies, we included ten independent transgenic lines plus eleven empty vector controls. Further in-depth studies were performed on up to three selected lines. At the time of harvest, plant height was measured from shoot tip to stem base (region of stem $6 \mathrm{~cm}$ above the soil surface). Stem diameter was measured at the base using calipers. Approximate leaf area was calculated by multiplying midrib length by maximum width, and averaging the estimates of five individual leaves between LPI-1(leaf plastochron index 1) to LPI-5 as described previously [27]. Plants were harvested between 12:00 PM and 2:00 PM. At the time of harvest, young leaf (LPI 1), mature leaf (LPI-6), young stem (internodes 1 to 3), mature stem (internodes 6 to 8), petiole of mature leaf, phloem (bark), xylem (stem scrapings) and root were collected. Immediately after harvest, phloem samples were frozen in dry ice, stem samples were air-dried, and the rest were frozen in liquid nitrogen and stored at $-80^{\circ} \mathrm{C}$ until used. For root architecture scans, plants growing in leach tubes were destructively harvested and scanned using Epson Perfection V700 photo scanner (Epson America Inc, Long Beach, CA), and root surface area was estimated using WinRhizo (Version 2012b) software. 


\section{Non-structural carbohydrate analysis}

Levels of sucrose and glucose were estimated as described previously [44] with slight modifications. Such that, ca. $20 \mathrm{mg}$ of freeze-dried sample was extracted thrice using a total of $2.0 \mathrm{ml}$ of $80 \%$ ethanol by incubating at $80^{\circ} \mathrm{C}$. The supernatants from the three extracts were combined and again extracted with $50 \mathrm{mg}$ activated charcoal to eliminate pigments. After centrifugation, the remaining pellet was used for starch analysis and supernatant for sugar estimation. The ethanol phase from the supernatant was eliminated by incubating the sample at $50^{\circ} \mathrm{C}$ for $18 \mathrm{hr}$. The pellet was dissolved in water $(800 \mu \mathrm{l}$ for leaf and $250 \mu \mathrm{l}$ for stem sample), vortexed and used for sucrose and glucose estimation using kits (Sigma, St Louis, MO). Starch from the pellet was estimated using enzymatic method and quantified using glucose standard as described previously $[27,45]$.

\section{Structural carbohydrate analysis}

Structural carbohydrates were extracted from the dried pellet after sugars and starch extraction. Briefly, $5 \mathrm{mg}$ of the extract-free sample was digested with $\mathrm{H}_{2} \mathrm{SO}_{4}(50 \mu \mathrm{l}$ of $72 \% \mathrm{v}: \mathrm{v}$ ) at $37^{\circ} \mathrm{C}$ for $60 \mathrm{~min}$. After diluting to a final concentration of $4 \% \mathrm{H}_{2} \mathrm{SO}_{4}$, the samples were autoclaved for $60 \mathrm{~min}$, cooled to room temperature and an aliquot was neutralized with $\mathrm{CaCO}_{3}$. Carbohydrate composition was estimated using high performance liquid chromatography (LaChrom Elite ${ }^{\circ}$ system, Hitachi High Technologies America, Inc.) equipped with a refractive index detector (model L-2490) and a UV-Vis detector (model L-2420) as described elsewhere [46,47].

\section{RNA extraction and qRT-PCR}

RNA was extracted using the Spectrum Plant Total RNA Kit (Sigma) with slight modification. To approximately $50 \mathrm{mg}$ frozen sample, $850 \mu \mathrm{l}$ of CTAB (cetyl trimethylammonium bromide) buffer (pre-warmed at $65^{\circ} \mathrm{C}$ ) and $10 \mu \mathrm{l}$ of $\beta$-mercaptoethanol (Sigma) was added, vortexed and incubated at $65^{\circ} \mathrm{C}$ for $5 \mathrm{~min}$. To the same tube $600 \mu \mathrm{l}$ of chloroform:isoamyl alcohol (24:1 v:v) was added and re-extracted. After centrifugation, the supernatant was passed through filter column (Sigma). After diluting the filtrate with $500 \mu \mathrm{l}$ of $95 \% \mathrm{EtOH}$, the combined liquid was passed through binding column. The binding column was then washed with Wash 1 solution and oncolumn DNAse digestion was carried out for 20 min as per the manufactures instructions (Sigma). The binding column was washed with wash buffers and RNA was eluted using 50-100 $\mu \mathrm{l}$ elution buffer. After quantifying RNA using NanoDrop, cDNA was prepared from $1500 \mathrm{ng}$ total RNA. qRT-PCR was performed using $3 \mathrm{ng}$ RNA equivalent cDNA, gene specific primers (200 nM) (primer sequences provided in Additional file 11) [48] and $1 Z$ SYBR green (Bio-Rad life sciences, Hercules,
CA) on the StepOnePlusTM Real-Time PCR system (Applied Biosystems, Grand Island, NY). Gene expression was calculated using $\Delta \mathrm{cT}$ or $\Delta \Delta \mathrm{cT}$ methods [49] based on the threshold cycle (cT) values of the target gene and the housekeeping genes, Ubiquitin-conjugating enzyme E2 (Potri.006G205700) and 18S ribosomal RNA (AF206999) (Additional file 11).

\section{Phenolics and pigment analysis}

Freeze-dried sample $(5 \mathrm{mg})$ was extracted twice with a total of $1.5 \mathrm{ml} 80 \% \mathrm{EtOH}$ using TissueLyzer (Qiagen, Valencia, CA) for $5 \mathrm{~min}$ at $30 \mathrm{~Hz}$. After 5 min centrifugation, the resulting supernatant was used for estimation of total phenolics, and pellet for tannin analysis. Total phenolics was estimated by using Folin-Ciocalteu reagent as described previously [50] with modification. In a 96-well plate, $10 \mu \mathrm{l}$ of extract, $150 \mu \mathrm{l}$ water and $10 \mu \mathrm{l}$ FC reagent (Sigma) were added, mixed. After $3 \mathrm{~min}$ incubation, $30 \mu \mathrm{l}$ of $20 \%$ sodium carbonate was added and again incubated at $40^{\circ} \mathrm{C}$. After $30 \mathrm{~min}$, absorbance at $\mathrm{A}_{755}$ was measured using a plate reader (SpectraMax, Molecular Devices, Sunnyvale, CA) and phenolic content was estimated based on the standard curve developed using chlorogenic acid. Tannins from the pellet were estimated using butanol: $\mathrm{HCl}(95: 5 \mathrm{v}: \mathrm{v})$ method as described elsewhere [51].

\section{Cellulose content}

The level of total cellulose content was estimated by the anthrone reagent method as described previously [52]. Sample (roughly $25 \mathrm{mg}$ air-dried and milled stem sample or $15 \mathrm{mg}$ freeze-dried leaf, phloem or petiole) was first digested with $500 \mu \mathrm{l}$ acetic-nitric reagent (10\% nitric acid in $80 \%$ acetic acid, v:v) at $98^{\circ} \mathrm{C}$ for $30 \mathrm{~min}$, followed by washing the pellet with $700 \mu \mathrm{l}$ water. After complete removal of water, the pellet was digested with $600 \mu \mathrm{l}$ of $67 \% \mathrm{H}_{2} \mathrm{SO}_{4}$ for $60 \mathrm{~min}$. After a 10-fold dilution with water, 10 to $50 \mu \mathrm{l}$ of diluted sample along with water to a final volume of $50 \mu \mathrm{l}$ were taken in $0.2 \mathrm{ml} \mathrm{PCR} \mathrm{tube,}$ added $100 \mu \mathrm{l}$ anthrone solution $\left(0.5 \mathrm{mg} \mathrm{ml}^{-1}\right.$ in $\left.\mathrm{H}_{2} \mathrm{SO}_{4}\right)$ and incubated at $98^{\circ} \mathrm{C}$ for $10 \mathrm{~min}$ in a thermal cycler. After cooling, the samples were transferred to a 96-well plate and absorbance at $\mathrm{A}_{630}$ was recorded and cellulose content was estimated based on the standard curve developed using glucose dilutions.

\section{Lignin content and its composition analysis}

Lignin and the ratio of its syringyl-to-guaiacyl units (S/G ratio) from air dried stem samples $(4 \mathrm{mg})$ were analyzed by pyrolysis molecular beam mass spectrometry (MBMS) at National Renewable Energy Laboratory, Golden, $\mathrm{CO}$ as described elsewhere [53]. 


\section{Metabolite profiling}

Individual metabolites were analyzed by metabolite profiling using gas chromatography-mass spectrometry (GC-MS). Briefly, 50-75 mg of finely ground fresh tissue sample were repeatedly extracted with $2.5 \mathrm{ml}$ of $80 \%$ ethanol, with the extracts then combined. A $1 \mathrm{ml}$ aliquot was dried in a nitrogen stream. After dissolving the dried extracts in acetonitrile followed by trimethylsilylation, metabolite profiling was performed by GC-MS, as described elsewhere [54,55]. Metabolites were identified based on mass spectral fragmentation patterns of electron impact ionization $(70 \mathrm{eV})$ and were quantified using peak areas of a characteristic mass-to-charge $(\mathrm{m} / \mathrm{z})$ ratio normalized to the internal standard (sorbitol) recovered and corrected for sample wieght. Some of the unidentified metabolites were denoted by their retention time (RT) and key $\mathrm{m} / \mathrm{z}$ ratio. The metabolite data were presented as fold changes of the transgenic line (average of 3 independent lines with 3 replicates for each line) vs. the average of the controls. Statistical significance was assessed using Student's $t$-test.

\section{Availability of supporting data}

All the data supporting our results are included in the article and in the Additional files.

\section{Additional files}

\section{Additional file 1: Protein sequence similarity/identity percentage} among selected UGPases.

Additional file 2: Protein sequence alignment of the two PdUGPase isoforms with that of previously characterized members.

Additional file 3: Phenotypic characterization of UGPase2 transgenic plants in preliminary study.

Additional file 4: Relative expression of UGPase2 in mature leaf petioles of control and the three transgenic lines.

Additional file 5: Metabolite levels in xylem of control and UGPase2 overexpression lines.

Additional file 6: Metabolite levels in phloem of control and UGPase2 overexpression lines.

Additional file 7: Unknown caffeoyl-glycosides in P. deltoides stem phloem of control plants but absent in overexpressed UGPase2 plants.

Additional file 8: Ratio of glycosides to aglycones of phenolics in phloem of control and UGPase2 overexpression lines.

Additional file 9: Metabolite levels in mature leaf of control and UGPase2 overexpression lines.

Additional file 10: Unknown caffeoyl-glycosides in P. deltoides leaves unique to overexpressed UGPase2 transgenic lines.

Additional file 11: List of gene primer sequences and gene models used in this study.

\section{Abbreviations}

ADP: Adenosine 5'-diphosphate; ATP: Adenosine triphosphate; 4CL: 4-coumarate:CoA ligase; CCR: Cinnamoyl-CoA reductase; CesA: Cellulose synthase; CT: Threshold cycle; CTAB: Cetyl trimethylammonium bromide; GC-MS: Gas chromatography-mass spectrometry; HPLC: High performance liquid chromatography; I-loop: Insertion loop; LPI: Leaf plastochron index; KOR: KORRIGAN; MBMS: Molecular beam mass spectrometry;
MEGA: Molecular evolutionary genetics analysis; NB-loop: Nucleotide binding loop; NIN: neutral invertase; qRT-PCR: Quantitative reverse transcriptase PCR; RNAi: RNA interference; RT: Retention time; S/G: Syringyl to guaiacyl ratio; SPS: Sucrose phosphate synthase; SuSy: Sucrose synthase; SUT: sucrose transporter; UDP: Uridine 5'-diphosphate; UTP: Uridine triphosphate; UGPase: UDP-glucose pyrophosphorylase; VIN: Vacuolar invertase.

\section{Competing interests}

The authors declare that they have no competing interests.

\section{Authors' contributions}

RSP, GAT and UCK designed the research, RSP, TJT, SSJ and RWS performed the experiments, RSP, TJT and UCK wrote the manuscript. All authors read and approved the manuscript

\section{Acknowledgements}

We thank Zackary Moore, Lee Gunter and Brock Carter for propagation and maintenance of plants in ORNL greenhouses; Xiaohan Yang, Will Rottmann, Kim Winkler and ArborGen LLC for binary construct development and plant transformation; Kelsey Yee and Mark Davis for HPLC runs of cell wall digests and MBMS analyses, respectively. We also thank Nancy Engle, Sara Allen and Madhavi Martin for assistance with metabolite analyses. This research was funded by the U.S. Department of Energy (DOE) BioEnergy Science Center project. The BioEnergy Science Center is a Bioenergy Research Center supported by the Office of Biological and Environmental Research in the DOE Office of Science. ORNL is managed by UT-Battelle, LLC for the U.S. Department of Energy under Contract Number DE-AC05-000R22725.

\section{Author details}

'BioEnergy Science Center and Biosciences Division, Oak Ridge National Laboratory, Oak Ridge, TN 37831, USA. ${ }^{2}$ The Biosciences Center, National Renewable Energy Laboratory, Golden, CO 80401, USA.

Received: 19 May 2014 Accepted: 25 September 2014

Published online: 07 October 2014

\section{References}

1. Koch K: Sucrose metabolism: regulatory mechanisms and pivotal roles in sugar sensing and plant development. Curr Opin Plant Biol 2004, 7(3):235-246.

2. Bar-Peled M, O'Neill MA: Plant nucleotide sugar formation, interconversion, and salvage by sugar recycling. Annu Rev of Plant Biol 2011, 62(1):127-155.

3. Gibeaut DM: Nucleotide sugars and glycosyltransferases for synthesis of cell wall matrix polysaccharides. Plant Physiol Biochem 2000, 38(1-2):69-80.

4. Tsai C-J, Harding SA, Tschaplinski TJ, Lindroth RL, Yuan Y: Genome-wide analysis of the structural genes regulating defense phenylpropanoid metabolism in Populus. New Phytol 2006, 172(1):47-62.

5. Winter H, Huber SC: Regulation of sucrose metabolism in higher plants: Localization and regulation of activity of key enzymes. $\mathrm{Cr}$ Revs Biochem Mol Biol 2000, 35(4):253-289.

6. Ermolaeva M, Wu M, Eisen J, Salzberg S: The age of the Arabidopsis thaliana genome duplication. Plant Mol Biol 2003, 51(6):859-866.

7. Chen R, Zhao X, Shao Z, Wei Z, Wang Y, Zhu L, Zhao J, Sun M, He R, He G: Rice UDP-glucose pyrophosphorylase 1 is essential for pollen callose deposition and its cosuppression results in a new type of thermosensitive genic male sterility. Plant Cell 2007, 19(3):847-861.

8. Meng M, Geisler M, Johansson H, Mellerowicz EJ, Karpinski S, Kleczkowski LA: Differential tissue/organ-dependent expression of two sucrose- and cold-responsive genes for UDP-glucose pyrophosphorylase in Populus. Gene 2007, 389(2):186-195.

9. Gustafson GL, Gander JE: Uridine diphosphate glucose pyrophosphorylase from Sorghum vulgare: Purification and kinetic properties. J Biol Chem 1972, 247(5):1387-1397.

10. Ginsburg V: Purification of uridinediphosphate glucose pyrophosphorylase from mung bean seedlings. J Biol Chem 1958, 232(1):55-61.

11. Kamogawa A, Kurahashi K: Purification and properties of uridinediphosphate glucose pyrophosphorylase from Escherichia coli $\mathrm{K}$ 12. J Biochem 1965, 57(6):758-765. 
12. Meng M, Wilczynska MAKL: Molecular and kinetic characterization of two UDP-glucose pyrophophorylases, products of distinct genes, from Arabidopsis. BBA - Proteins Proteom 2008, 1784(6):967-972.

13. Johansson H: Gene Regulation of UDP-Glucose Synthesis and Metabolism in Plants. Umeå University, Department of Plant Physiology: PhD Thesis; 2003.

14. Coleman HD, Ellis DD, Gilbert M, Mansfield SD: Up-regulation of sucrose synthase and UDP-glucose pyrophosphorylase impacts plant growth and metabolism. Plant Biotechnol J 2006, 4(1):87-101.

15. Coleman HD, Canam T, Kang K-Y, Ellis DD, Mansfield SD: Over-expression of UDP-glucose pyrophosphorylase in hybrid poplar affects carbon allocation. J Exp Bot 2007, 58(15-16):4257-4268.

16. Zrenner R, Willmitzer $L$, Sonnewald $U$ : Analysis of the expression of potato uridinediphosphate-glucose pyrophosphorylase and its inhibition by antisense RNA. Planta 1993, 190(2):247-252.

17. Spychalla JP, Scheffler BE, Sowokinos JR, Bevan MW: Cloning, antisense RNA inhibition, and the coordinated expression of UDP-glucose pyrophosphorylase with starch biosynthetic genes in potato tubers. J Plant Physiol 1994, 144(4-5):444-453.

18. Borovkov AY, McClean PE, Sowokinos JR, Ruud SH, Secor GA: Effect of expression of UDP-glucose pyrophosphorylase ribozyme and antisense RNAs on the enzyme activity and carbohydrate composition of field-grown transgenic potato plants. J Plant Physiol 1995, 147(6):644-652.

19. Hertzberg M, Aspeborg H, Schrader J, Andersson A, Erlandsson R, Blomqvist K, Bhalerao R, Uhlen M, Teeri TT, Lundeberg J, Sundberg B, Nilsson P, Sandberg G: A transcriptional roadmap to wood formation. Proc Natl Acad Sci U S A 2001, 98(25):14732-14737.

20. Tuskan GA, DiFazio S, Jansson S, Bohlmann J, Grigoriev I, Hellsten U, Putnam N, Ralph S, Rombauts S, Salamov A, Schein J, Sterck L, Aerts A, Bhalerao RR, Bhalerao RP, Blaudez D, Boerjan W, Brun A, Brunner A, Busov V, Campbell M, Carlson J, Chalot M, Chapman J, Chen G-L, Cooper D, Coutinho PM, Couturier J, Covert S, Cronk Q, et al: The genome of black cottonwood, Populus trichocarpa (Torr. \& Gray). Science 2006, 313(5793):1596-1604

21. Peneff C, Ferrari P, Charrier V, Taburet $Y$, Monnier C, Zamboni V, Winter J, Harnois M, Fassy F, Bourne $Y$ : Crystal structures of two human pyrophosphorylase isoforms in complexes with UDPGIc(Gal)NAc: role of the alternatively spliced insert in the enzyme oligomeric assembly and active site architecture. EMBO J 2001, 20(22):6191-6202.

22. Steiner T, Lamerz A-C, Hess P, Breithaupt C, Krapp S, Bourenkov G, Huber R, Gerardy-Schahn R, Jacob U: Open and closed structures of the UDP-glucose pyrophosphorylase from Leishmania major. J Biol Chem 2007, 282(17):13003-13010

23. Kleczkowski LA, Martz F, Wilczynska M: Factors affecting oligomerization status of UDP-glucose pyrophosphorylase. Phytochem 2005, 66(24):2815-2821.

24. Decker D, Meng M, Gornicka A, Hofer A, Wilczynska MAKL: Substrate kinetics and substrate effects on the quaternary structure of barley UDP-glucose pyrophosphorylase. Phytochem 2012, 79:39-45.

25. Meng M, Geisler M, Johansson H, Harholt J, Scheller HV, Mellerowicz EJ, Kleczkowski LA: UDP-Glucose pyrophosphorylase is not rate limiting, but is essential in Arabidopsis. Plant Cell Physiol 2009, 50(5):998-1011.

26. Mahboubi A, Ratke C, Gorzsás A, Kumar M, Mellerowicz EJ, Totte N: Aspen Sucrose transporter 3 allocates carbon into wood fibers. Plant Physiol 2013, 163(4):1729-1740.

27. Payyavula RS, Tay KHC, Tsai C-J, Harding SA: The sucrose transporter family in Populus: the importance of a tonoplast PtaSUT4 to biomass and carbon partitioning. Plant J 2011, 65(5):757-770.

28. Maloney VJ, Mansfield SD: Characterization and varied expression of a membrane-bound endo- $\beta-1,4$-glucanase in hybrid poplar. Plant Biotechnol J 2010, 8(3):294-307.

29. Somerville C: Cellulose synthesis in higher plants. Annu Rev Cell Dev Biol 2006, 22(1):53-78.

30. Joshi CP, Thammannagowda S, Fujino T, Gou J-Q, Avci U, Haigler CH, McDonnell LM, Mansfield SD, Mengesha B, Carpita NC, Harris D, DeBolt S, Peter GF: Perturbation of wood cellulose synthesis causes pleiotropic effects in transgenic aspen. Mol Plant 2011, 4(2):331-345.

31. Kalluri U, Hurst G, PK L, Ranjan P, Pelletier DA: Shotgun proteome profile of Populus developing xylem. Proteomics 2009, 21:4871-4880

32. Haigler $\mathrm{CH}$, Ivanova-Datcheva $M$, Hogan $P$, Salinikov V: Carbon partitioning to cellulose synthesis. Plant Mol Biol 2001, 47:29-51.

33. Coleman HD, Yan J, Mansfield SD: Sucrose synthase affects carbon partitioning to increase cellulose production and altered cell wall ultrastructure. Proc Natl Acad Sci U S A 2009, 106(31):13118-13123.
34. Valla S, Coucheron D, Fjervik E, Kjosbakken J, Weinhouse H, Ross P, Amikam $D$, Benziman M: Cloning of a gene involved in cellulose biosynthesis in Acetobacter xylinum: Complementation of cellulose-negative mutants by the UDPG pyrophosphorylase structural gene. Mol Gen Genet 1989, 217(1):26-30.

35. Leple J-C, Dauwe R, Morreel K, Storme V, Lapierre C, Pollet B, Naumann A, Kang K-Y, Kim H, Ruel K, Lefebvre A, Joseleau J-P, Grima-Pettenati J, De Rycke R, Andersson-Gunneras S, Erban A, Fehrle I, Petit-Conil M, Kopka J, Polle A, Messens E, Sundberg B, Mansfield SD, Ralph J, Pilate G, Boerjan W: Downregulation of Cinnamoyl-Coenzyme A reductase in Poplar: Multiple-level phenotyping reveals effects on cell wall polymer metabolism and structure. Plant Cell 2007, 19(11):3669-3691.

36. Voelker SL, Lachenbruch B, Meinzer FC, Jourdes M, Ki C, Patten AM, Davin LB, Lewis NG, Tuskan GA, Gunter L, Decker SR, Selig MJ, Sykes R, Himmel ME, Kitin P, Shevchenko O, Strauss SH: Antisense down-regulation of $4 C L$ expression alters lignification, tree growth, and saccharification potential of field-grown poplar. Plant Physiol 2010, 154(2):874-886.

37. Babst BA, Chen H-Y, Wang H-Q, Payyavula RS, Thomas TP, Harding SA, Tsai C-J: Stress-responsive hydroxycinnamate glycosyltransferase modulates phenylpropanoid metabolism in Populus. J Exp Bot 2014, 65(15):4191-4200.

38. Gachon CMM, Langlois-Meurinne M, Saindrenan P: Plant secondary metabolism glycosyltransferases: the emerging functional analysis. Trends Plant Sci 2005, 10(11):542-549.

39. Zhang G, Qi J, Xu J, Niu X, Zhang Y, Tao A, Zhang L, Fang P, Lin L: Overexpression of UDP-glucose pyrophosphorylase gene could increase cellulose content in Jute (Corchorus capsularis L.). Biochem Bioph Res Co 2013, 442(3-4):153-158.

40. Sato S, Kato T, Kakegawa K, Ishii T, Liu Y-G, Awano T, Takabe K, Nishiyama Y, Kuga S, Sato S, Nakamura Y, Tabata S, Shibata D: Role of the putative membrane-bound endo-1,4-b-glucanase KORRIGAN in cell elongation and cellulose synthesis in Arabidopsis thaliana. Plant Cell Physiol 2001, 42(3):251-263.

41. Goodstein DM, Shu S, Howson R, Neupane R, Hayes RD, Fazo J, Mitros T, Dirks W, Hellsten U, Putnam N, Rokhsar DS: Phytozome: a comparative platform for green plant genomics. Nucl Acids Res 2012, 40(D1):D1178-D1186.

42. Tamura K, Peterson D, Peterson N, Stecher G, Nei M, Kumar S: MEGA5: molecular evolutionary genetics analysis using maximum likelihood, evolutionary distance, and maximum parsimony methods. Mol Biol Evol 2011, 28(10):2731-2739.

43. Nicholas KB, Nicholas HBJ, Deerfield DWl: GeneDoc: analysis and visualization of genetic variation. EMBNEW NEWS 1997, 4:14

44. Payyavula RS, Navarre D, Kuhl J, Pantoja A, Pillai S: Differential effects of environment on potato phenylpropanoid and carotenoid expression. BMC Plant Biol 2012, 12(1):39.

45. Chow PS, Landhäusser SM: A method for routine measurements of total sugar and starch content in woody plant tissues. Tree Physiol 2004, 24(10):1129-1136.

46. Yee K, Rodriguez M Jr, Tschaplinski T, Engle N, Martin M, Fu C, Wang Z-Y, Hamilton-Brehm S, Mielenz J: Evaluation of the bioconversion of genetically modified switchgrass using simultaneous saccharification and fermentation and a consolidated bioprocessing approach. Biotechnol Biofuels 2012, 5(1):81.

47. Fu C, Mielenz JR, Xiao X, Ge Y, Hamilton CY, Rodriguez M, Chen F, Foston M, Ragauskas A, Bouton J, Dixon RA, Wang Z-Y: Genetic manipulation of lignin reduces recalcitrance and improves ethanol production from switchgrass. Proc Natl Acad Sci U S A 2011, 108(9):3803-3808.

48. Payyavula RS, Babst B, Nelsen M, Harding S, Tsai C-J: Glycosylation-mediated phenylpropanoid partitioning in Populus tremuloides cell cultures. BMC Plant Biol 2009, 9(1):151.

49. Livak KJ, Schmittgen TD: Analysis of relative gene expression data using real-time quantitative $P C R$ and the $2^{\wedge}$ [-delta delta $C(T)$ ] method. Methods 2001, 25(4):402-408.

50. Singleton $V L$, Rossi $J A$ : Colorimetry of total phenolics with phosphomolybdic-phosphotungstic acid reagents. Am J Enol Viticul 1965, 16(3):144-158

51. Porter LJ, Hrstich LN, Chan BG: The conversion of procyanidins and prodelphinidins to cyanidin and delphinidin. Phytochem 1985, 25(1):223-230.

52. Updegraff DM: Semimicro determination of cellulose in biological material. Anal Biochem 1969, 32:420-424.

53. Sykes R, Yung M, Novaes E, Kirst M, Peter G, Davis M: High-throughput screening of plant cell-wall composition using Pyrolysis Molecular Beam 
Mass Spectroscopy. In Biofuels: Methods and Protocols. volume 581. Edited by Mielenz JR. New York: Humana Press; 2009:169-183.

54. Jung HW, Tschaplinski TJ, Wang L, Glazebrook J, Greenberg JT: Priming in systemic plant immunity. Science 2009, 324(5923):89-91.

55. Li Y, Tschaplinski T, Engle N, Hamilton C, Rodriguez M Jr, Liao J, Schadt C, Guss A, Yang Y, Graham D: Combined inactivation of the Clostridium cellulolyticum lactate and malate dehydrogenase genes substantially increases ethanol yield from cellulose and switchgrass fermentations. Biotechnol Biofuels 2012, 5(2):1-13.

doi:10.1186/s12870-014-0265-8

Cite this article as: Payyavula et al:: Metabolic profiling reveals altered sugar and secondary metabolism in response to UGPase overexpression in Populus. BMC Plant Biology 2014 14:265.

\section{Submit your next manuscript to BioMed Central and take full advantage of:}

- Convenient online submission

- Thorough peer review

- No space constraints or color figure charges

- Immediate publication on acceptance

- Inclusion in PubMed, CAS, Scopus and Google Scholar

- Research which is freely available for redistribution 